\title{
A comparison of propofol and midazolam/meperidine sedation in upper gastrointestinal endoscopy
}

\author{
Sinan Uzman ${ }^{1}$, Bunyamin Gurbulak², Esin Kabul Gurbulak ${ }^{3}$, Turgut Donmez ${ }^{4}$, Adnan Hut ${ }^{5}$, Dogan Yildirim ${ }^{5}$ \\ ${ }^{1}$ Department of Anesthesiology and Reanimation, Haseki Training and Research Hospital, Istanbul, Turkey \\ ${ }^{2}$ Department of General Surgery, Arnavutkoy State Hospital, Istanbul, Turkey \\ ${ }^{3}$ Department of General Surgery, Şişli Hamidiye Etfal Training and Research Hospital, Istanbul, Turkey \\ ${ }^{4}$ Department of General Surgery Lutfiye Nuri Burat State Hospital, Istanbul, Turkey \\ ${ }^{5}$ Department of General Surgery, Haseki Training and Research Hospital, Istanbul, Turkey
}

Videosurgery Miniinv 2016; 11 (3): 178-185

DOI: $10.5114 /$ wiitm.2016.61521

\begin{abstract}
Introduction: There is increasing interest in sedation for upper gastrointestinal endoscopy (UGE). Prospective randomized studies comparing sedation properties and complications of propofol and midazolam/meperidine in upper gastrointestinal endoscopy (UGE) are few.

Aim: To compare propofol and midazolam/meperidine sedation for UGE in terms of cardiopulmonary side effects, patient and endoscopist satisfaction and procedure-related times.

Material and methods: This was a prospective, randomized, double-blind study of propofol versus midazolam and meperidine in 100 patients scheduled for diagnostic upper gastrointestinal endoscopy. The patients were divided into propofol and midazolam/meperidine groups. Randomization was generated by a computer. Cardiopulmonary side effects (hypotension, bradycardia, hypoxemia), procedure-related times (endoscopy time, awake time, time to hospital discharge), and patient and endoscopist satisfaction were compared between groups.

Results: There was no significant difference between the groups with respect to the cost, endoscopy time, or demographic and clinical characteristics of the patients. Awake time and time to hospital discharge were significantly shorter in the propofol group (6.58 \pm 4.72 vs. $9.32 \pm 4.26 \mathrm{~min}, p=0.030$ and $27.60 \pm 7.88$ vs. $32.00 \pm 10.54 \mathrm{~min}, p=$ 0.019). Hypotension incidence was significantly higher in the propofol group ( $12 \% \mathrm{vs.} 0 \%, p=0.027)$. The patient and endoscopist satisfaction was better with propofol.

Conclusions: Propofol may be preferred to midazolam/meperidine sedation, with a shorter awake and hospital discharge time and better patient and endoscopist satisfaction. However, hypotension risk should be considered with propofol, and careful evaluation is needed, particularly in cardiopulmonary disorders.
\end{abstract}

Key words: gastrointestinal endoscopy, propofol, midazolam, meperidine, moderate sedation.

\section{Introduction}

Esophagogastroduodenoscopy (EGD) is an invasive outpatient procedure that has been widely used for the diagnosis, treatment, screening, and follow-up of various upper gastrointestinal diseases [1-4]. Applica- tion of sedation and analgesia during the procedure provides increased tolerance, comfort, and satisfaction by decreasing the gag reflex, dizziness, and vomiting, and improves the efficiency of the procedure [5-7].

Midazolam is a short-acting, water-soluble benzodiazepine that inhibits the central nervous system

\section{Address for correspondence}

Sinan Uzman MD, PhD, Department of Anesthesiology and Reanimation, Haseki Training and Research Hospital, Adnan Adivar Str, Fatih, 34100 Istanbul, Turkey, phone: +90 5055645271, e-mail: drsinanuzman@yahoo.com 
by binding to $\gamma$-aminobutyric acid type $A\left(G_{A B A}\right)$ receptors. It has anxiolytic, sedative-hypnotic, anticonvulsant, and antegrade amnestic properties [8]. The combination of opioid analgesic meperidine with midazolam is the most frequently used sedation regimen in gastrointestinal endoscopy worldwide [9]. Propofol (2,6-diisopropyl phenol) has faster sedation induction and shorter half-life compared to midazol$\mathrm{am} /$ meperidine, and its use has increased annually [7, 9-12]. In spite of its advantages, propofol has no analgesic effect. Moreover, propofol sedation may readily provide general anesthesia at higher doses and, contrary to midazolam and meperidine, it has no pharmacological antagonist [13].

Although many studies and meta-analyses on the effectiveness, sedation properties, and complications of propofol or midazolam/meperidine in upper gastrointestinal endoscopy (UGE) exist, prospective randomized studies comparing these two regimens are few $[5,9,10-15]$.

\section{Aim}

We aimed to compare the sedation properties, cardiopulmonary side effects, risk factors, as well as patient and endoscopist satisfaction of propofol and midazolam/meperidine.

\section{Material and methods}

\section{Study design and patient selection}

This was a prospective, randomized, double-blind study to compare propofol and midazolam/meperidine sedation. The study was conducted in the Endoscopy Center of our hospital. The study protocol was approved by the local Hospital Ethics Committee, conducted according to the Declaration of Helsinki, and all patients provided written informed consent.

A hundred out of the 125 consecutive patients who underwent elective outpatient diagnostic UGE between February 2014 and June 2014 were included in the study. Exclusion criteria were: known sensitivity or allergy to study drugs, egg, and soybean oil; age < 18 years; pregnant or breast-feeding; risk of difficult intubation (i.e., short-thick neck, inability to widely open the mouth, Mallampati class III-IV); history of obstructive sleep apnea syndrome; American Society of Anesthesiologists (ASA) physical classification status > III; and history of complications in previous sedations.
All endoscopies were performed by the same general surgeon, who had more than 5 years of experience in gastrointestinal tract endoscopy and who was blinded to the aim of the study. The patients, endoscopy, and recovery room nurse were also unaware of the aim of the study. Patients were allocated to the propofol (group P) and meperidine/ midazolam (group MM) groups by computer-generated simple randomization. All sedation protocols were performed by the same anesthesiologist who was also blinded to the aim of the study.

\section{Sedation protocol}

All the patients received $0.9 \%$ sodium chloride at $10 \mathrm{ml} / \mathrm{kg} / \mathrm{h}$ intravenously and $3 \mathrm{l} / \mathrm{min}$ oxygen via nasal cannula in the endoscopy unit. The phar$y n x$ of the patients was topically anesthetized with three puffs of lidocaine spray (Xylocaine pump spray $10 \%$, AstraZeneca Inc., Turkey) before the procedure. In group P, sedation was performed with an initial bolus of $1 \mathrm{mg} / \mathrm{kg}$ propofol (propofol 2\%, Fresenius Kabi, Istanbul, Turkey) intravenously followed by repeated doses of 10 to $20 \mathrm{mg}$ propofol intravenously, as needed, for continuous sedation. In group MM, sedation was started with a bolus dose of $0.4 \mathrm{mg} / \mathrm{kg}$ meperidine (Aldolan, Liba Lab, Istanbul, Turkey) intravenously followed three minutes later by $0.05 \mathrm{mg} /$ kg midazolam intravenously (Dormicum, Roche, Istanbul, Turkey), and sedation was maintained with repeated intravenous doses of 5 to $10 \mathrm{mg}$ meperidine and 1 to $2 \mathrm{mg}$ midazolam. The level of sedation was evaluated with the Observer's Assessment of Alertness/Sedation Scale (OAA/S), every one minute after the initial bolus injection of propofol or meperidine/midazolam (Table I) [16]. A moderate sedation

Table I. Observer's assessment of alertness/sedation scale (OAA/S)

\begin{tabular}{|lc|}
\hline Observation & Score level \\
\hline $\begin{array}{l}\text { Responds readily to name spoken } \\
\text { in normal tone }\end{array}$ & 5 \\
\hline $\begin{array}{l}\text { Lethargic response to name spoken } \\
\text { in normal tone }\end{array}$ & 3 \\
\hline $\begin{array}{l}\text { Responds only after name is called loudly } \\
\text { and/or repeatedly }\end{array}$ & 2 \\
\hline Responds only after mild prodding or shaking & 1 \\
\hline Responds only after painful trapezius squeeze & 0 \\
\hline $\begin{array}{l}\text { Does not respond to painful trapezius } \\
\text { squeeze }\end{array}$ & \\
\hline
\end{tabular}


level was provided throughout the procedure (OAA/S 2-4). Flumazenil (Anexate, Deva, Istanbul, Turkey) and naloxone (Naloxone Hydrochloride, Abbott, Istanbul, Turkey), the antagonists of midazolam and meperidine, as well as all the equipment needed for resuscitation, were available in the endoscopy room.

\section{Patient monitoring and data collection}

In the endoscopy unit, electrocardiography (ECG), heart rate (HR), noninvasive blood pressure (NIBP), respiratory rate $(R R)$, and peripheral oxygen saturation $\left(\mathrm{SpO}_{2}\right)$ were monitored continuously in all the patients with a standard monitoring device (Draeger Infinity Delta, Draeger Medical Systems, Inc. Telford, PA, USA) before the application of topical anesthesia until discharge from the hospital. All monitoring parameters, duration of endoscopy, awake time (i.e., time for the patient to have an OAA/S score of 5 in the recovery room), time to hospital discharge after the endoscopy, cardiopulmonary side effects, and patient characteristics were recorded by the same research resident, who was unaware of the group assignment of each patient.

\section{Cardiopulmonary side effects and treatment}

The NIBP measurements were automatically performed every two minutes throughout the endoscopy; thereafter NIBP was measured every 5 min until hospital discharge. $\mathrm{HR}, \mathrm{RR}$, and $\mathrm{SpO}_{2}$ were evaluated continuously. Cardiopulmonary side effects included: 1) hypotension (i.e., more than 30\% decrease in baseline mean arterial pressure (MAP) or systolic arterial pressure (SAP) $<90 \mathrm{~mm} \mathrm{Hg}$, 2) bradycardia $(\mathrm{HR}<50 \mathrm{bpm}), 3)$ hypoxemia $\left(\mathrm{SpO}_{2}<90 \%\right.$ on oxygen supplementation), 4) apnea (arrest of respiration more than $15 \mathrm{~s}), 5$ ) other causes (i.e., arrhythmia, chest pain, or pulmonary edema), and 6) permanent brain damage and death. An additional $250 \mathrm{ml}$ isotonic saline solution was infused into patients who developed hypotension. Five $\mathrm{mg}$ of ephedrine was administered to patients whose hypotension was not corrected by ephedrine or whose systolic arterial pressure was $<90 \mathrm{~mm} \mathrm{Hg}$. Bradycardia was treated with intravenous atropine $0.5 \mathrm{mg}$. If $\mathrm{SpO}_{2}<90 \%$ continued for more than $15 \mathrm{~s}$, the chin lift maneuver was used. If $\mathrm{SpO}_{2} 90 \%$ did not rise above $90 \%$ in spite of the chin lift maneuver, assisted ventilation was applied and flumazenil and/ or naloxone was injected.

\section{Post-procedural follow-up and discharge evaluation}

Following the endoscopy, the patients were transferred to the recovery room. The blood pressure, HR, and $\mathrm{SpO}_{2}$ values were measured and patient consciousness was evaluated by the same recovery room nurse who was also unaware of the patient's group assignment. Patients without hypotension (mean arterial pressure $<70 \mathrm{~mm} \mathrm{Hg}$ ), bradycardia $(\mathrm{HR}<60 \mathrm{bpm})$, and hypoxemia $\left(\mathrm{SpO}_{2}<95 \%\right.$ in room air), who could sit in bed without help, and who were fully conscious (OAA/S score 5) were determined to be ready for discharge from the hospital.

\section{Evaluation of patient satisfaction}

The patients were asked by the recovery room nurse to evaluate the endoscopic procedure. They were asked to give a score for the pain, discomfort, or gag reflex that they experienced during the procedure ( $0=$ none, $100=$ severe $)$ and the level of sedation satisfaction ( 0 = very dissatisfied, 100 = very satisfied) on a $100 \mathrm{~mm}$ visual analog scale (VAS). They were also asked if they remembered waking up (yes/no) during the procedure.

\section{Evaluation of the endoscopist's satisfaction}

The endoscopist was asked to evaluate his or her satisfaction with sedation ( $0=$ very dissatisfied, $100=$ very satisfied) using the VAS.

\section{Procedure-related times}

Procedure-related times were defined were as follows: 1) endoscopy time (i.e., the time interval between the start of UGE and endoscope removal), 2) awake time (i.e., the time interval between endoscope removal and patient reaching an OAA/S score of 5), and 3) time to hospital discharge (i.e., the time interval between endoscope removal and hospital discharge).

\section{Statistical analysis}

The SPSS software package for Windows (Statistical Package for Social Sciences, version 17.0, SPSS Inc., Chicago, IL, USA) was used for statistical analysis. Quantitative variables including age, body mass index (BMI), procedure-related times, drug dose, as well as patient and endoscopist satisfaction, were expressed as mean \pm standard deviation (SD). Cate- 
gorical variables such as patient characteristics and adverse events were expressed as the number and percentage of patients. Quantitative variables were analyzed with the Kolmogorov-Smirnov test to assess the normality of the data distribution, and normally distributed variables were compared with Student's $t$-test. The $\chi^{2}$ or Fisher's exact test was used to compare categorical variables.

To calculate the sample size for this study, the incidence of adverse cardiopulmonary events including hypotension and hypoxemia was assumed to be approximately 34\% for propofol sedation, as was found in a previous study [17]. Power analysis with $\alpha=0.05$ and $\beta=0.2$ to determine a $50 \%$ reduction in adverse cardiopulmonary events with meperidine and midazolam revealed that each group required a minimum of 36 patients. A value of $p<0.05$ was taken to be statistically significant.

\section{Results}

\section{Patient characteristics}

One hundred and twenty-five consecutive patients who underwent elective outpatient diagnostic UGIE were enrolled in the study. Twelve patients did not fulfill the inclusion criteria, 6 patients did not wish to participate, and 7 patients were lost to follow-up. Ultimately, 50 patients in both groups were analyzed (Figure 1).

None of the patients developed endoscopy-related complications. The most frequent indication for UGIE was epigastric pain/discomfort $(n=62)$. Other indications were nausea and vomiting $(n=16)$, anemia $(n=7)$, dysphagia $(n=6)$, hematemesis $(n=5)$, and weight loss $(n=4)$. There were no significant differences between the groups in terms of age, gender, ASA classification, BMI, smoking/alcohol use, presence of comorbid diseases, or history of medical treatment and surgery. The mean total dose of propofol administered was $88.0 \pm 26.1 \mathrm{mg}$; the mean midazolam and meperidine doses were $3.61 \pm 0.91$ $\mathrm{mg}$ and $28.92 \pm 5.96 \mathrm{mg}$, respectively (Table II).

\section{Procedure-related times}

The results of the comparisons of endoscopy time, awake time, and time to hospital discharge between the two groups are summarized in Table III. There was no significant difference between the two groups in terms of endoscopy time $(p=0.145)$. We found that awake time and time to hospital discharge were significantly shorter with propofol compared to meperidine/midazolam (awake time: $p=0.030$, time to hospital discharge: $p=0.019$; Table III).

\section{Adverse cardiopulmonary events}

The incidence rates of adverse cardiopulmonary events are summarized in Table III. We observed significantly more adverse cardiopulmonary events with propofol compared to meperidine/midazolam ( $20 \%$ vs. $4 \%, p=0.025$ ). Hypotension incidence was significantly higher in the propofol group compared to the meperidine/midazolam group ( $12 \%$ vs. $0 \%$, $p=0.027)$. The difference between the groups with respect to hypoxemia incidence and apnea incidence was not statistically significant ( $p=0.160$ and $p=0.362$, respectively). No patients showed permanent damage, death, or bradycardia.

\section{Satisfaction}

Patient and endoscopist satisfaction for the two groups were compared, and their results are summarized in Table IV. None of the patients remembered the UGIE procedure. Patients in group P experienced significantly less discomfort/pain and/or

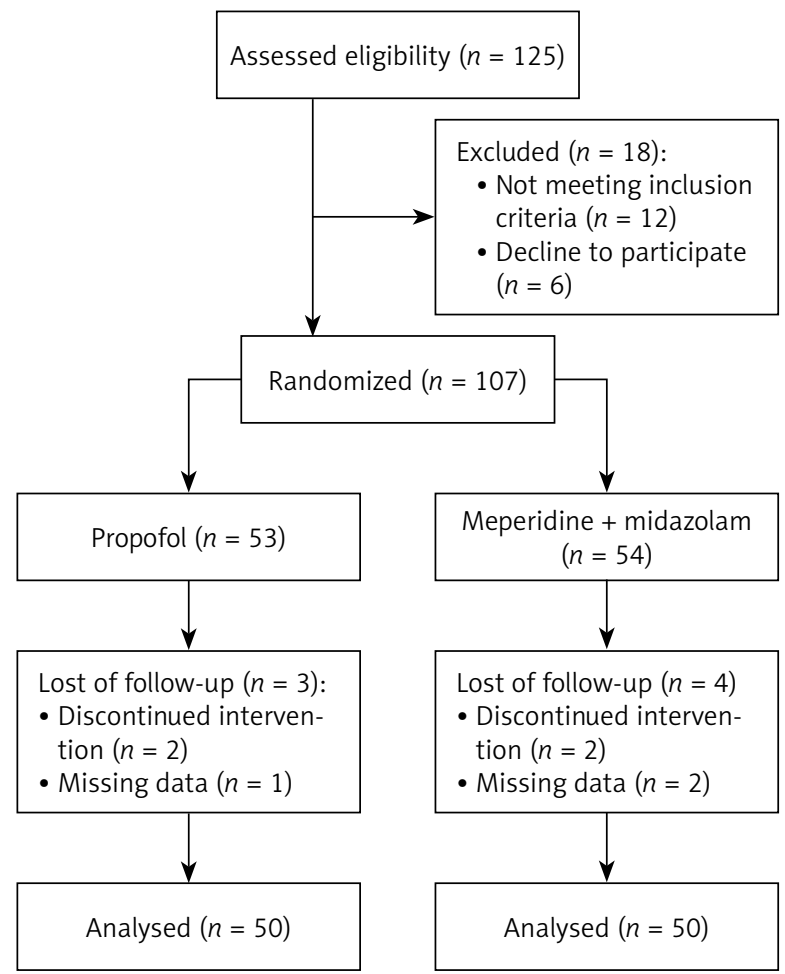

Figure 1. Flowchart of the study 
Table II. Characteristics of patients

\begin{tabular}{|c|c|c|c|}
\hline Characteristics & Propofol $(n=50)$ & $M / M(n=50)$ & $P$-value \\
\hline Age [years] & $47 \pm 17$ & $41 \pm 15$ & 0.052 \\
\hline Gender, M/F & $23 / 27$ & $21 / 29$ & 0.840 \\
\hline BMI $\left[\mathrm{kg} / \mathrm{cm}^{2}\right]$ & $27.0 \pm 4.8$ & $26.6 \pm 5.3$ & 0.681 \\
\hline ASA classification: & & & 0.256 \\
\hline I & 35 & 40 & \\
\hline$\|$ & 13 & 10 & \\
\hline III & 2 & 0 & \\
\hline Tobacco/alcohol use & 8 & 10 & 0.374 \\
\hline Co-existing disease: & 18 & 15 & 0.523 \\
\hline Cardiovascular disorders & 12 & 8 & \\
\hline Diabetes mellitus & 2 & 3 & \\
\hline Others & 6 & 8 & \\
\hline Medical treatment: & 18 & 15 & 0.523 \\
\hline Cardiovascular drugs & 12 & 8 & \\
\hline Oral antidiabetics & 2 & 3 & \\
\hline Others & 6 & 8 & \\
\hline Operation history: & 19 & 18 & 0.682 \\
\hline Gastrointestinal surgery & 5 & 8 & \\
\hline Others & 15 & 11 & \\
\hline \multicolumn{4}{|l|}{ Total drug dose [mg]: } \\
\hline Propofol & $88.0 \pm 26.1$ & - & \\
\hline Meperidine & - & $28.92 \pm 5.96$ & \\
\hline Midazolam & - & $3.61 \pm 0.91$ & \\
\hline
\end{tabular}

Data are given as mean $\pm S D$ or number and percent of cases. $A S A-$ American Society of Anesthesiologists, $B M I-$ body mass index, M/M: midazolam + meperidine.

Table III. Procedure-related times and adverse events

\begin{tabular}{|lccc|}
\hline Variable & Propofol $(n=50)$ & M/M $(n=50)$ & $P$-value \\
\hline Endoscopy time $[\mathrm{min}]$ & $7.60 \pm 2.68$ & $8.38 \pm 2.63$ & 0.145 \\
\hline Awake time [min] & $6.58 \pm 4.72$ & $9.32 \pm 4.26$ & 0.030 \\
\hline Time to hospital discharge [min] & $27.60 \pm 7.88$ & $32.00 \pm 10.54$ & 0.019 \\
\hline Adverse events: & $10(20)$ & $2(4)$ & 0.025 \\
\hline Hypoxemia & $7(14)$ & $2(4)$ & 0.160 \\
\hline Apnea & $4(8)$ & $1(2)$ & 0.362 \\
\hline Hypotension & $6(12)$ & $0(0)$ & 0.027 \\
\hline Bradycardia & $0(0)$ & $0(0)$ & $>0.999$ \\
\hline Permanent damage or death & $0(0)$ & $0(0)$ & $>0.999$ \\
\hline
\end{tabular}

Data are presented as mean $\pm S D$ or number (\%) of the patients. $M / M-$ midazolam + meperidine. 
Table IV. Patient's and endoscopist's satisfaction

\begin{tabular}{|lccc|}
\hline Variable & Propofol $(n=50)$ & M/M $(n=50)$ & $P$-value \\
\hline Patient's discomfort/pain and/or gagging & $8.3 \pm 3.7$ & $11.4 \pm 5.4$ & $<0.001$ \\
\hline Patient satisfaction & $92.5 \pm 5.1$ & $89.2 \pm 6.7$ & 0.007 \\
\hline Recollection of the procedure (yes/no) & $0 / 50$ & $0 / 50$ & 1.000 \\
\hline Endoscopist satisfaction & $85.2 \pm 4.6$ & $79.7 \pm 5.9$ & $<0.001$ \\
\hline
\end{tabular}

Data are presented as mean $\pm S D$ or number of patients. $M / M-$ midazolam + meperidine.

gagging compared to group MM $(p<0.001)$. These results also showed higher patient and endoscopist satisfaction in group P $(p=0.007$ and $p<0.001$, respectively).

\section{Discussion}

Esophagogastroduodenoscopy is an essential and widely accepted minimal invasive tool for diagnosing, treating, and screening upper gastrointestinal disorders $[18,19]$. The use of sedation for EGD varies from country to country and even differs within the same country because of social, cultural, economic, and regulatory influences [20]. Although EGD can be safely carried out without sedation, nowadays the vast majority of EGDs in developed countries are performed while the patient is sedated $[10,21,22]$.

The goal of sedation during EGD is to improve patient satisfaction by decreasing anxiety and embarrassment, relieve pain, and prevent recollection of the procedure. In spite of this, most of the adverse cardiopulmonary events during endoscopy are related to sedation [23]. The most common sedation regimen for EGD worldwide is propofol and midazolam with an opioid such as meperidine, and propofol use has been gaining in popularity because of increased endoscopist satisfaction compared to traditional sedation in recent years $[10,20,22]$.

In this study, we found that midazolam/meperidine is superior to propofol with respect to the occurrence of adverse cardiopulmonary events, particularly hypotension. All of the patients who had hypotension were in the propofol group (12\%), and this was a significant difference. Transient hypotension was sufficiently corrected by fluid loading, and there was no need for vasopressor treatment in any patients. Although hypoxemia and apnea were more frequently associated with propofol, no significant difference was detected between the groups (Table III). The chin lift maneuver was necessary in 4 (8\%) patients in group $\mathrm{P}$ and 1 (2\%) patient in group MM to address apnea. Hypoxemia and apnea were quickly addressed with the chin lift maneuver and by increasing the rate of nasal oxygen flow, and there was no need for endotracheal intubation and mechanical ventilation or for flumazenil and/or naloxone injection.

Previous studies have reported that propofol and meperidine/midazolam have a similar cardiopulmonary safety profile. In a meta-analysis that included 12 randomized controlled studies, Qadeer et al. concluded that the risk of cardiopulmonary complications during EGD was similar in propofol sedation compared to midazolam [12]. In a recent meta-analysis of eight randomized controlled studies involving EGD (425 patients) that compared propofol sedation with midazolam, there was no difference in cardiopulmonary complications between propofol and midazolam [24]. A prospective randomized study by Vargo et al. [15] found no difference between propofol and meperidine/midazolam sedation with respect to adverse cardiopulmonary event incidence during advanced upper endoscopic procedures. Their observed incidence of hypotension in the propofol group $(15.9 \%)$ was comparable to our findings, but it was much higher in the meperidine/midazolam group $(18.9 \%)$ compared to our findings. The percentage of other adverse events such as hypoxemia and apnea that we observed was lower than the percentages reported by Vargo et al. [15], due to the larger doses of propofol and meperidine/midazolam used in their study. Moreover, another study found that propofol sedation does not increase the risk of hypotension compared to midazolam sedation, even in patients with cirrhosis [25].

Contrary to the studies mentioned above, a closed claim analysis in the USA found that propofol has a higher incidence of cardiorespiratory complications than non-propofol-based sedation during endoscopy [26]. Gangi et al. [27] stated that propofol is 
an independent risk factor for adverse cardiovascular events in endoscopic procedures of the digestive system. In a retrospective analysis, Goudra et al. [28] found that the number of cardiac arrests during EGD with propofol sedation was 14 in 12,166 patients and in non-propofol-based sedation was zero in 15,108 patients, and that cardiac arrests were primarily related to airway problems that resulted in hypoxemia.

Procedure-related times were compared between the groups, and the results of the present study demonstrate that awake time and time to hospital discharge were significantly shorter for propofol sedation compared to meperidine/midazolam sedation. These findings are comparable to those of other studies [15, 24, 25, 29, 30]. In a recent meta-analysis, propofol sedation was shown to reduce recovery time and discharge time compared to midazolam with or without meperidine, and no significant difference in amnesia was detected between the two sedation regimens after EGD [24]. Propofol seems to be more favorable compared to meperidine/midazolam for short procedures such as EGD, in terms of faster recovery and earlier discharge.

We found that propofol had better patient and endoscopist satisfaction and no patients reported recollection of the procedure. These results align with a number of previous studies [10, 22, 29, 31]. In contrast, three recent meta-analyses reported no differences in patient and endoscopist satisfaction between propofol and meperidine/midazolam sedation for endoscopic procedures [24, 32, 33]. This difference may be related to medication dose, patient characteristics (e.g., age, gender), sedation level, and the low sample size of the studies.

\section{Conclusions}

The results obtained in this study revealed that propofol sedation has a faster recovery time and earlier discharge after EGD, as compared to meperidine/ midazolam sedation. Although a high satisfaction level was observed with both sedation regimens, patient and endoscopist satisfaction was significantly greater for propofol sedation. Compared with meperidine/midazolam, adverse cardiopulmonary events seem to be higher with propofol. Complications can be prevented with strict monitoring of peripheral oxygen saturation, HR, blood pressure, electrocardiography, and oxygen supplementation. Propofol may be preferable for short procedures such as EGD, but it should be used carefully with trained staff.

\section{Acknowledgments}

English editing of the manuscript was performed by American Manuscript Editors (www.americanmanuscripteditors).

\section{Conflict of interest}

The authors declare no conflict of interest.

\section{References}

1. Azzam NA, Almadi MA, Alamar HH, et al. Performance of American Society for Gastrointestinal Endoscopy guidelines for dyspepsia in Saudi population: prospective observational study. World J Gastroenterol 2015; 21: 637-43.

2. Alatise OI, Aderibigbe AS, Adisa AO, et al. Management of overt upper gastrointestinal bleeding in a low resource setting: a real world report from Nigeria. BMC Gastroenterol 2014; 14: 210-8.

3. Choi KS, Suh M. Screening for gastric cancer: the usefulness of endoscopy. Clin Endosc 2014; 47: 490-6.

4. Radovanović N, Simić A, Skrobić O, et al. Highly selective vagotomy and gastrojejunostomy in the treatment of peptic ulcer induced gastric outlet obstruction. Vojnosanit Pregl 2014; 71: 1013-7.

5. Ozel AM, Oncü K, Yazgan Y, et al. Comparison of the effects of intravenous midazolam alone and in combination with meperidine on hemodynamic and respiratory responses and on patient compliance during upper gastrointestinal endoscopy: a randomized, double-blind trial. Turk J Gastroenterol 2008; 19: 8-13.

6. Tandon M, Pandey VK, Dubey GK, et al. Addition of sub-anaesthetic dose of ketamine reduces gag reflex during propofol based sedation for upper gastrointestinal endoscopy: a prospective randomised double-blind study. Indian J Anaesth 2014; 58: 436-41.

7. Lera dos Santos ME, Maluf-Filho F, Chaves DM, et al. Deep sedation during gastrointestinal endoscopy: propofol-fentanyl and midazolam-fentanyl regimens. World J Gastroenterol 2013; 19: 3439-46.

8. Reves JG, Fragen RJ, Vinik HR, Greenblatt DJ. Midazolam: pharmacology and uses. Anesthesiology 1985; 62: 310-24.

9. Triantafillidis JK, Merikas E, Nikolakis D, Papalois AE. Sedation in gastrointestinal endoscopy: current issues. World J Gastroenterol 2013; 19: 463-81.

10. Riphaus A, Geist F, Wehrmann T. Endoscopic sedation and monitoring practise in Germany: re-evaluation from the first nationwide survey 3 years after the implementation of an evidence and consent based national guideline. Z Gastroenterol 2013; 51: 1082-8.

11. Ferreira AO, Cravo M. Sedation in gastrointestinal endoscopy: where are we at in 2014? World J Gastrointest Endosc 2015; 7: 102-9. 
12. Qadeer MA, Vargo JJ, Khandwala F, et al. Propofol versus traditional sedative agents for gastrointestinal endoscopy: a meta-analysis. Clin Gastroenterol Hepatol 2005; 3: 1049-56.

13. Standarts of Practice Committee of the American Society for Gastrointestinal Endoscopy, Lichtenstein DR, Jagannath S, Baron TH, et al. Sedation and anesthesia in Gl endoscopy. Gastrointest Endosc 2008; 68: 815-26.

14. Anqsuwatcharakon P, Rerknimitr R, Ridtitid W, et al. Coctail sedation containing propofol versus conventional sedation for ERCP: a prospective, randomized controlled study. BMC Anesthesiol 2012; 12: 20.

15. Vargo JJ, Zuccaro G Jr, Durmot JA, et al. Gastroenterologist-administered propofol versus meperidine and midazolam for advanced endoscopy: a prospective, randomized trial. Gastroenterology 2002; 123: 8-16.

16. Chernik DA, Gillings D, Laine $H$, et al. Validity and reliability of the Observer's Assessment of Alertness/Sedation Scale: study with intravenous midazolam. J Clin Psychopharmacol 1990; 10: 244-51.

17. de Paulo GA, Martins FP, Macedo EP, et al. Sedation in gastrointestinal endoscopy: a prospective study comparing nonanesthesiologist-administered propofol and monitored anesthesia care. Endosc Int Open 2015; 3: E7-13.

18. Cerqueira R, Fernandes C, Correia M, Manso MC. Indications for upper gastrointestinal endoscopy. The accuracy of the American Society for Gastrointestinal Endoscopy guidelines in a Portuguese hospital. Acta Med Port 2008; 21: 427-32.

19. ASGE Standards of Practice Committee, Early DS, Ben-Menachem T, Decker GA, et al. Appropriate use of GI endoscopy. Gastrointest Endosc 2012; 75: 1127-31.

20. Benson AA, Cohen LB, Waye JD, et al. Endoscopic sedation in developing and developed countries. Gut Liver 2008; 2: 105-12.

21. Fisher NC, Bailey S, Gibson JA. A prospective, randomized controlled trial of sedation vs. no sedation in outpatient diagnostic upper gastrointestinal endoscopy. Endoscopy 1998; 30: 21-4.

22. Cohen LB, Wecsler JS, Gaetano JN, et al. Endoscopic sedation in the United States: results from a nationwide survey. Am J Gastroenterol 2006; 101: 967-74.

23. Sieg A, Hachmoeller-Eisenbach U, Eisenbach T. Prospective evaluation of complications in outpatient GI endoscopy: a survey among German gastroenterologists. Gastrointest Endosc 2001; 53: 620-7.

24. Wang D, Chen C, Chen J, et al. The use of propofol as a sedative agent in gastrointestinal endoscopy: a meta-analysis. PLoS One 2013; 8: e53311.

25. Tsai HC, Lin YC, Ko CL, et al. Propofol versus midazolam for upper gastrointestinal endoscopy in cirrhotic patients: a metaanalysis of randomized controlled trials. PLoS One 2015; 10: e0117585.

26. Metzner J, Posner KL, Domino KB. The risk and safety of anesthesia at remote locations: the US closed claims analysis. Curr Opin Anaesthesiol 2009; 22: 502-8.

27. Gangi S, Saidi F, Patel K, et al. Cardiovascular complications after Gl endoscopy: occurrence and risks in a large hospital system. Gastrointest Endosc 2004; 60: 679-85.

28. Goudra B, Nuzat A, Singh PM, et al. Cardiac arrests in patients undergoing gastrointestinal endoscopy: a retrospective analysis of 73,029 procedures. Saudi J Gastroenterol 2015; 21: 400-11.
29. Dewitt J, McGreevy K, Sherman S, Imperiale TF. Nurse-administered propofol sedation compared with midazolam and meperidine for EUS: a prospective, randomized trial. Gastrointest Endosc 2008; 68: 499-509.

30. Carlsson U, Grattidge P. Sedation for upper gastrointestinal endoscopy: a comparative study of propofol and midazolam. Endoscopy 1995; 27: 240-3.

31. Koshy G, Nair S, Norkus EP, et al. Propofol versus midazolam and meperidine for conscious sedation in Gl endoscopy. Am J Gastroenterol 2000; 95: 1476-9.

32. Singh $H$, Poluha $W$, Cheung $M$, et al. Propofol for sedation during colonoscopy. Cochrane Database Syst Rev 2008; 4: CD006268.

33. McQuaid KR, Laine L. A systematic review and meta-analysis of randomized, controlled trials of moderate sedation for routine endoscopic procedures. Gastrointest Endosc 2008; 67: 910-23.

Received: 18.03.2016, accepted: 15.07.2016 